OAK RIDGE
$\frac{\text { NATIONAL LABORATORY }}{\text { MANAGED BY UT-BATTELLE }}$
FOR THE DEPARTMENT OF ENERGY

\section{CALIBRATION OF SMALL PLASTIC SCINTILLATORS FOR IMAGING APPLICATIONS}

Sara A. Pozzi, James A. Mullens, and John T. Mihalczo

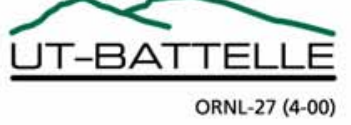




\section{DOCUMENT AVAILABILITY}

Reports produced after January 1, 1996, are generally available free via the U.S. Department of Energy (DOE) Information Bridge.

Web site http://www.osti.gov/bridge

Reports produced before January 1, 1996, may be purchased by members of the public from the following source.

National Technical Information Service

5285 Port Royal Road

Springfield, VA 22161

Telephone 703-605-6000 (1-800-553-6847)

TDD 703-487-4639

Fax 703-605-6900

E-mail info@ntis.fedworld.gov

Web site http://www.ntis.gov/support/ordernowabout.htm

Reports are available to DOE employees, DOE contractors, Energy Technology Data Exchange (ETDE) representatives, and International Nuclear Information System (INIS) representatives from the following source.

Office of Scientific and Technical Information

P.O. Box 62

Oak Ridge, TN 37831

Telephone 865-576-8401

Fax 865-576-5728

E-mail reports@adonis.osti.gov

Web site http://www.osti.gov/contact.html

This report was prepared as an account of work sponsored by an agency of the United States Government. Neither the United States government nor any agency thereof, nor any of their employees, makes any warranty, express or implied, or assumes any legal liability or responsibility for the accuracy, completeness, or usefulness of any information, apparatus, product, or process disclosed, or represents that its use would not infringe privately owned rights. Reference herein to any specific commercial product, process, or service by trade name, trademark, manufacturer, or otherwise, does not necessarily constitute or imply its endorsement, recommendation, or favoring by the United States Government or any agency thereof. The views and opinions of authors expressed herein do not necessarily state or reflect those of the United States Government or any agency thereof. 
ORNL/TM-2004/298

Nuclear Science and Technology Division

\title{
CALIBRATION OF SMALL PLASTIC SCINTILLATORS FOR IMAGING APPLICATIONS
}

\author{
Sara A. Pozzi, James A. Mullens, \\ and John T. Mihalczo
}

Date published: December 2004

Prepared by

OAK RIDGE NATIONAL LABORATORY

Oak Ridge, Tennessee 37831-6285

managed by

UT-BATTELLE, LLC

for the

U.S. DEPARTMENT OF ENERGY

under contract DE-AC05-00OR22725 



\section{TABLE OF CONTENTS}

Page

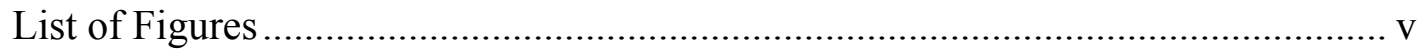

List of Tables ......................................................................................... vii

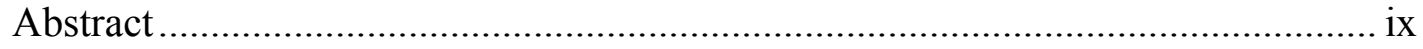

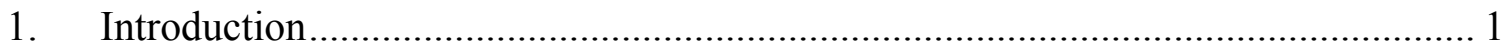

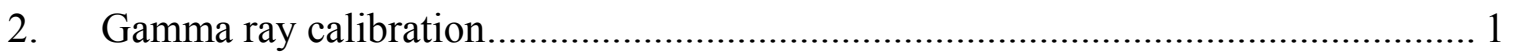

3. Cf-252 time of flight measurements ............................................................. 3

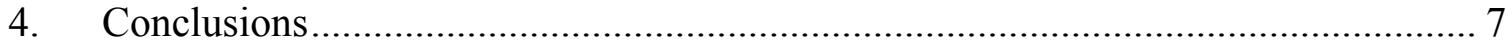

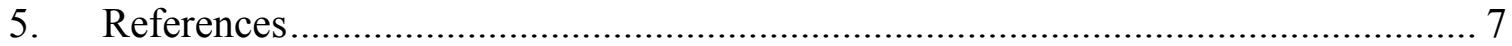





\section{LIST OF FIGURES}

Figure

Page

1. Pulse height as a function of voltage for the Cs-137 Compton edge. 2

2. Pulse height distributions for Cs-137 source placed on (a) detector top and

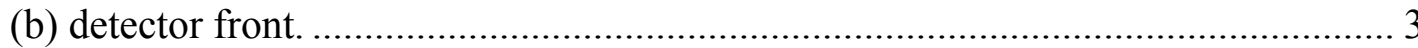

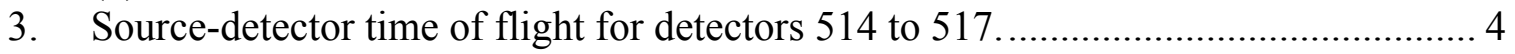

4. Simulated time of flight distribution, with neutron and photon contributions shown.

5. Comparison between Monte Carlo simulation and measurement for source-detector time of flight.... 



\section{LIST OF TABLES}

Table

Page

1. Voltages corresponding to a $100-\mathrm{mV}$ pulse height for Cs-137

Compton edge.

2. Parameters used in the post-processing code ................................................. 5

3. Percent error in the MCNP-PoliMi simulation of measurements:

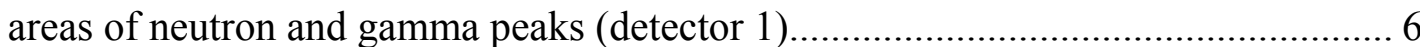





\title{
Calibration of Small Plastic Scintillators for Imaging Applications
}

\author{
Sara A. Pozzi, James A. Mullens, and John T. Mihalczo \\ Oak Ridge National Laboratory \\ Oak Ridge, TN 37831-6010 PO Box 2008 Ms6010
}

\begin{abstract}
This report presents the results of measurements and simulations performed with 12 small plastic scintillation detectors manufactured by Scionix for imaging applications. The scintillator is equivalent to a Bicron BC-420 plastic scintillator. A gamma calibration is presented to determine the voltage to be applied on each detector to ensure uniform detector operation. Time of flight measurements performed with a Cf-252 source are also presented. Comparisons between experimental data and data from the Monte Carlo simulations show good agreement for time lags of 0 to $70 \mathrm{~ns}$.
\end{abstract}





\title{
Calibration of small plastic scintillators for imaging applications
}

\author{
Sara A. Pozzi, James A. Mullens, and John T. Mihalczo \\ Oak Ridge National Laboratory \\ Oak Ridge, TN 37831-6010 PO Box 2008 Ms6010
}

\section{Introduction}

Twelve small plastic scintillation detectors manufactured by Scionix are being studied for imaging applications [1]. The active volume of the detectors is $2.54 \times 2.54 \times 15.0 \mathrm{~cm}$. First, a gamma calibration was performed to determine the pulse heights as a function of voltage on each detector. Then, the voltages were set so that the detectors had a uniform response. Time of flight measurements using Cf-252 and four detector channels were performed to verify uniform detector operation. A comparison between these measurements and Monte Carlo simulations is also presented.

\section{Gamma ray calibration}

A Cs-137 source was used to acquire pulse heights for each detector for voltages varying from -700 to $-900 \mathrm{~V}$. The acquisition was performed with the fast digital scope Tektronix TDS 5104. The pulse shapes were acquired and stored for offline analysis. The measurement time for the acquisition of 1500 pulses was approximately $2 \mathrm{~s}$. In the measurements, the gamma source was placed on top of the detector, approximately halfway along the length of the detector's active region.

A histogram of the pulse heights was computed offline, and the corresponding Compton edge was identified by selecting the half-height of the maximum value for pulse height distribution. Figure 1 shows the results of these measurements as a function of voltage for the 12 detectors. Table 1 gives the voltages for the 12 detectors corresponding to a Cs-137 Compton edge of $100 \mathrm{mV}$. In these measurements, the discriminator is traditionally set at one-third of the Cs-137 Compton edge value. 


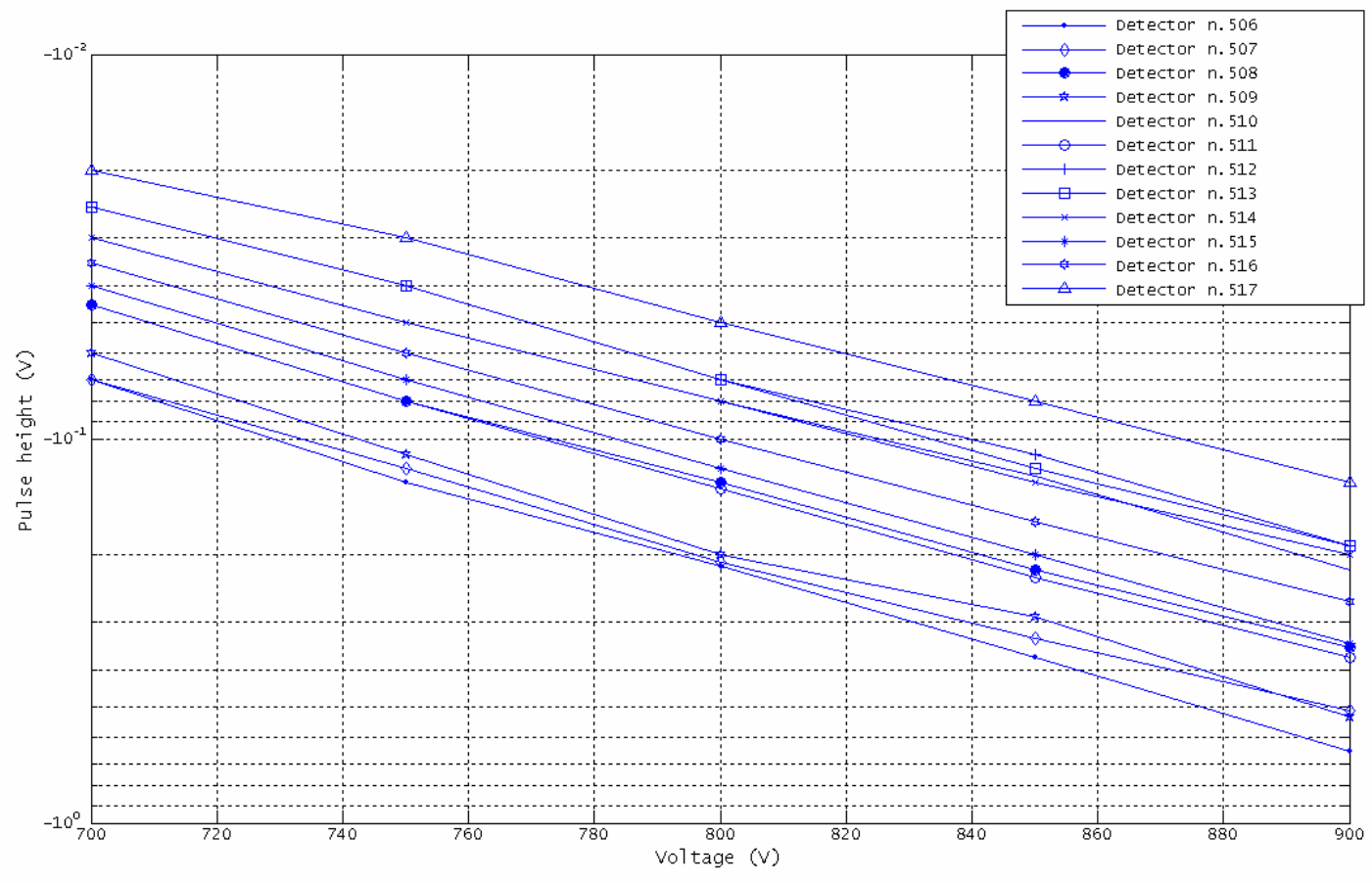

Fig. 1. Pulse height as a function of voltage for the Cs-137 Compton edge.

Table 1. Voltages corresponding to a 100-mV pulse height for Cs-137

Compton edge.

\begin{tabular}{cc}
\hline $\begin{array}{c}\text { Detector } \\
\text { serial number }\end{array}$ & $\begin{array}{c}\text { Voltage } \\
(\mathrm{V})\end{array}$ \\
\hline 506 & -730 \\
507 & -735 \\
508 & -772 \\
509 & -743 \\
510 & -822 \\
511 & -772 \\
512 & -840 \\
513 & -832 \\
514 & -822 \\
515 & -785 \\
516 & -800 \\
517 & -875 \\
\hline
\end{tabular}


Figure 2 shows the comparison of two pulse height distributions, corresponding to two different positions of the Cs-137 source on the detector. The pulse height distribution of Fig. 2(a) was obtained by placing the Cs-137 source on top of the detector, approximately halfway along the length of the detector's active region. The pulse height distribution of Fig. 2(b) was obtained by placing the source on the detector's front face. The data in Fig. 2 were taken with detector number 517 at $-900 \mathrm{~V}$. Visual inspection shows that the source positioning does not affect on pulse heights considerably.
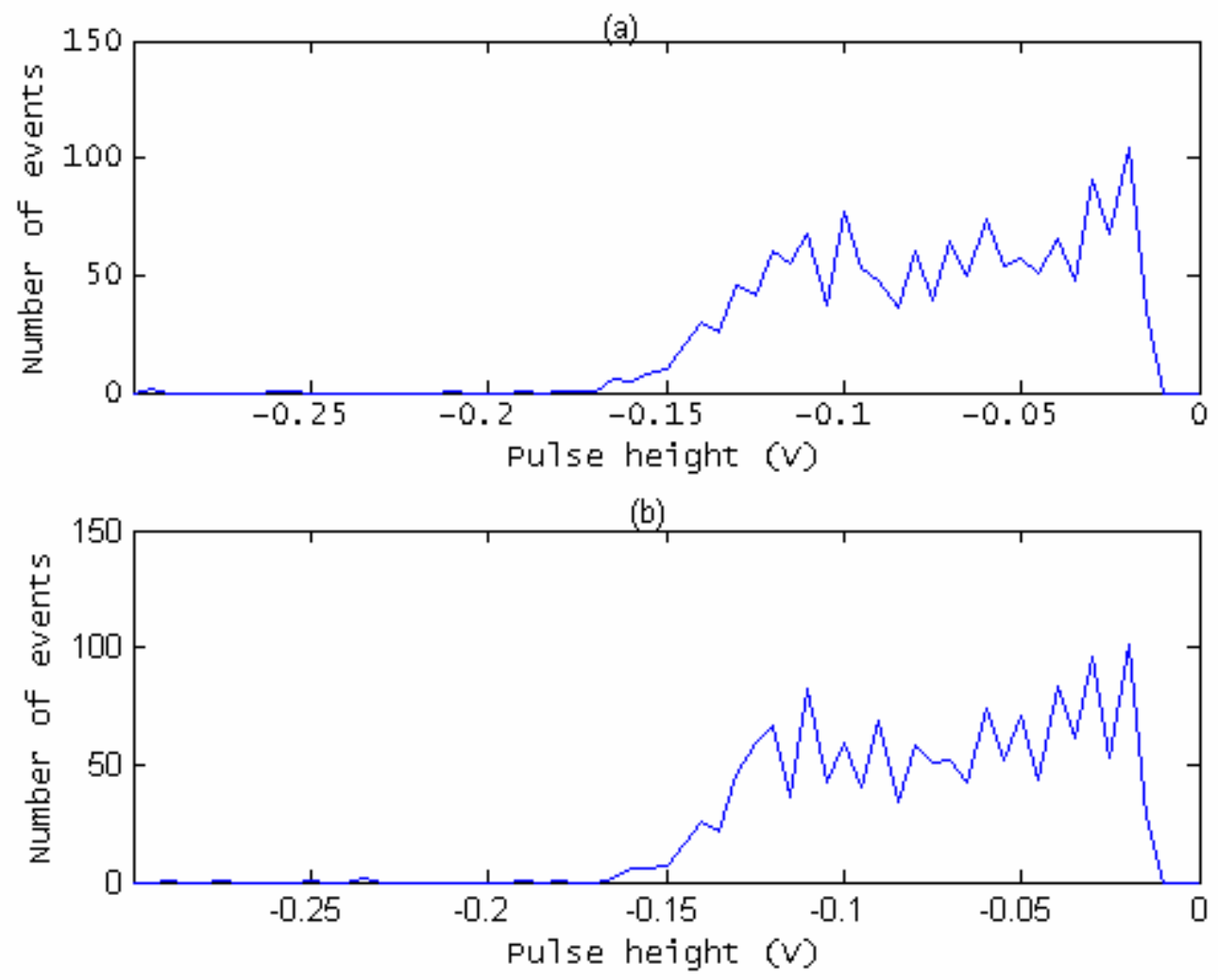

Fig. 2. Pulse height distributions for Cs-137 source placed on (a) detector top and (b) detector front.

\section{Cf-252 time of flight measurements}

Time of flight measurements were performed with the Nuclear Materials Identification System [2], using an instrumented Cf-252 source and four detector channels. The detectors were placed $100 \mathrm{~cm}$ from the $\mathrm{Cf}-252$ source. The source-detector time of flight was acquired for four detectors at a time. The detectors were placed side by side on a metal cart, at a height of $89.5 \mathrm{~cm}$ from the floor, with a distance of $6 \mathrm{~cm}$ between detectors. 
The detector voltages were adjusted according to the values given in Table 1. Using these voltages, a gamma ray energy deposition of $477 \mathrm{keV}$ (the Cs-137 Compton edge) generates pulses with an amplitude of $100 \mathrm{mV}$. The CFD threshold on the detectors was set to one-third of the Cs-137 Compton edge-i.e., $33 \mathrm{mV}$. Because the gamma ray energy to light output response in scintillators is essentially linear, this threshold corresponds to a gamma energy deposition of approximately $159 \mathrm{keV}$. The sourcedetector time of flight was acquired with these experimental settings and is shown in Fig. 3 for four detectors (numbers 514 to 517).

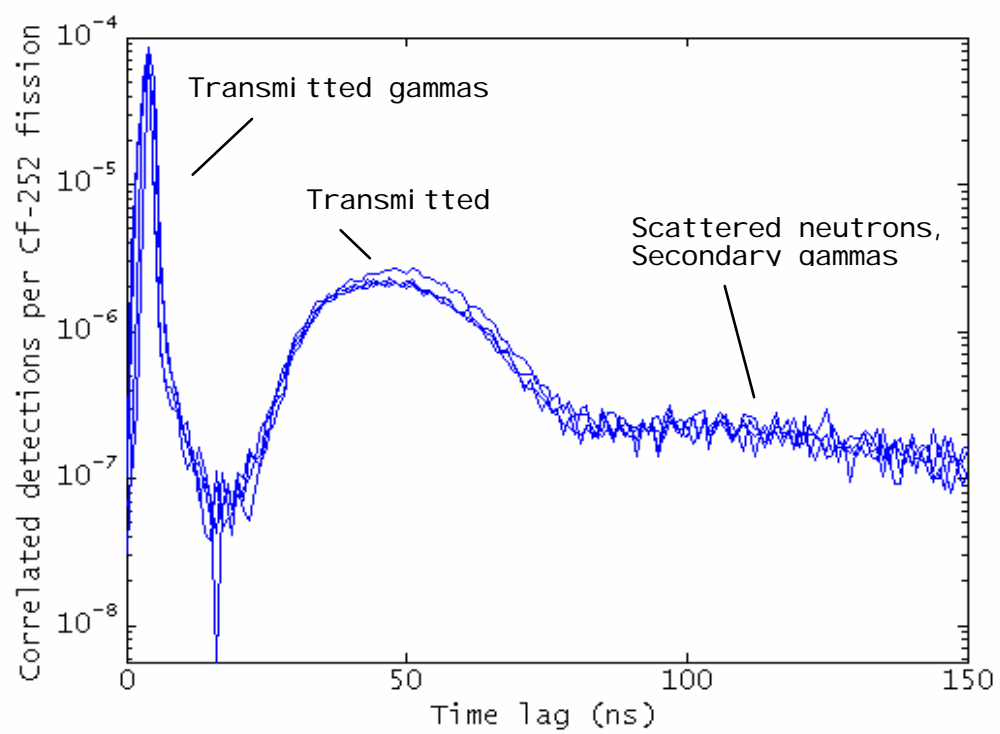

Fig. 3. Source-detector time of flight for detectors 514 to 517.

The source-detector time of flight shown in Fig. 4 was modeled using the MCNPPoliMi code [3]. The parameters used in the post-processing code are given in Table 2. The light output threshold was determined using the calibration described in Section 2 and the considerations of the preceding paragraph. The neutron light output was measured for liquid and plastic scintillators in a previous study [4] and is

$$
l=0.0364 \cdot E_{n}^{2}+0.125 E_{n}
$$

for the plastic scintillator BC-420, where $l$ is the light output in MeVee, and $E_{n}$ is the energy deposited by the neutron in a collision with hydrogen $(\mathrm{MeV})$.

The neutron energy threshold for the settings used in the experiments can thus be determined to be approximately $1 \mathrm{MeV}$. In this study, the detector dead time was set to $0 \mathrm{~ns}$. This can be justified by considering the absence of multiplication (no fissile 
material is present) and the small dimensions of the scintillators. It is therefore rare that more than one particle from each Cf-252 fission reaches a detector.

Table 2. Parameters used in the postprocessing code

\begin{tabular}{ll}
\hline Parameter & Value \\
\hline Dead time & $0 \mathrm{~ns}$ \\
Pulse generation time & $10 \mathrm{~ns}$ \\
Neutron energy threshold & $0.99 \mathrm{MeV}$ \\
Light output threshold & $0.1590 \mathrm{MeVee}$ \\
\hline
\end{tabular}

Figure 4 shows the result of one Monte Carlo simulation, for a source-detector correlation. The model included the metal cart on which the detectors were placed, the floor, two lab benches on either side of the cart, the detector PMT tube, and the aluminum housing of the detector. The number of Cf-252 source events was 200E6, and the run time was approximately $19 \mathrm{~h}$. Figure 4 also shows the time of flight signature subdivided into its neutron and photon components.

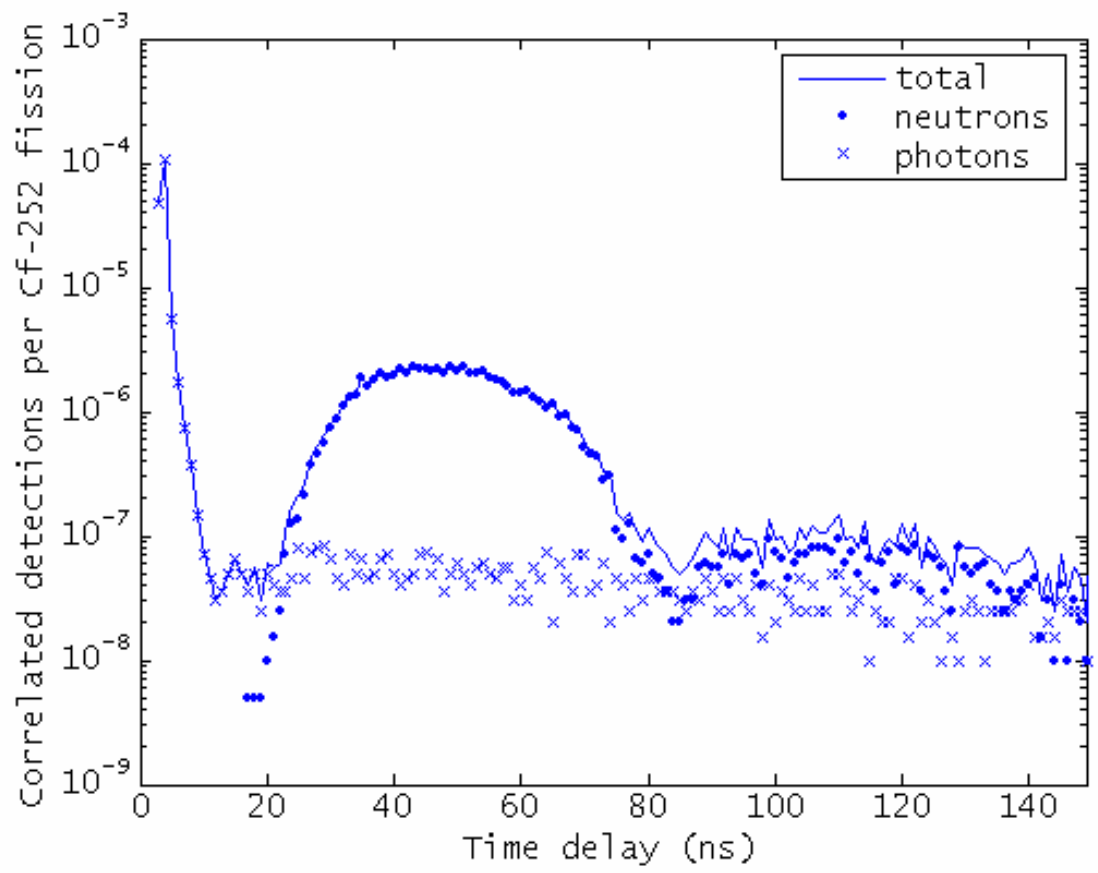

Fig. 4. Simulated time of flight distribution, with neutron and photon contributions shown. 
Figure 5 shows a comparison of the Monte Carlo simulation and the experiment performed with NMIS. Both simulation and experiment were normalized to the total number of Cf-252 fission events. The result shown in Figure 6 is for one of the detectors placed at the beginning of the four-detector array. The agreement is very good in the gamma peak and in the neutron peak, up to time lags of approximately 70 ns. The "tail" in the measurement is consistently greater than that predicted by the Monte Carlo simulation. A possible explanation of this discrepancy is that the measurement was performed in a room that contained many scattering elements that were not modeled in the simulation. The percentage error of the MCNP-PoliMi prediction of the gamma and neutron peaks is given in Table 3.

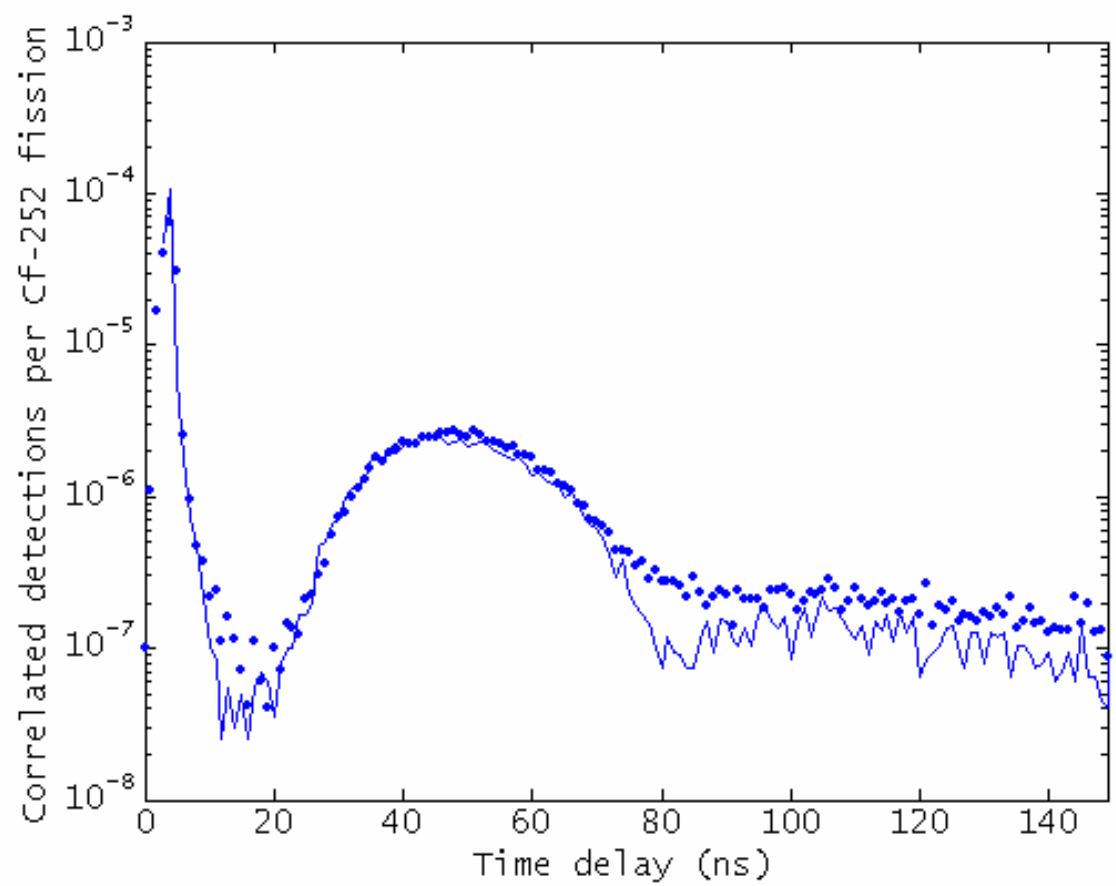

Fig. 5. Comparison between Monte Carlo simulation and measurement for source-detector time of flight.

Table 3. Percent error in the MCNP-PoliMi simulation of measurements: areas of neutron and gamma peaks (detector 1)

\begin{tabular}{cc}
\hline Parameter & Percent error \\
\hline Gamma peak & +0.6 \\
Neutron peak & -6.2 \\
\hline
\end{tabular}




\section{Conclusions}

In this report, we presented the results of measurements performed on 12 plastic scintillators that will be used for imaging applications. A gamma ray calibration was performed using a Cs-137 source. This calibration allowed us to determine the operating voltages for the 12 detectors, which varied from -730 to $-875 \mathrm{~V}$. Time of flight measurements performed with an instrumented Cf-252 source were also performed. Monte Carlo simulations of these measurements showed good agreements in the 0 to $70 \mathrm{~ns}$ time lag. The error in the prediction of the gamma peak was lower than $0.6 \%$ and the error in the neutron peak approximately $-6 \%$. The ability to predict the results of these measurements gives confidence in the simulations that are being used to plan and analyze future measurements.

\section{References}

1. J. A. Mullens, J. T. Mihalczo, and P. R. Bingham, "Neutron and Gamma Ray Imaging for Nuclear Materials Identification," Proceedings of the Institute of Nuclear Materials Managers 45th Annual Meeting, July 2004.

2. J. T. Mihalczo, J. A. Mullens, J. K. Mattingly, and T. E. Valentine, "Physical Description of Nuclear Materials Identification System (NMIS) Signatures," Nuclear Instruments and Methods in Physics Research Section A 450 (August 2000): 531.

3. S. A. Pozzi, E. Padovani, and M. Marseguerra, "MCNP-PoliMi: A Monte Carlo Code for Correlation Measurements," Nuclear Instruments and Methods in Physics Research A 513, no. 3 (2003): 550-558.

4. S. A. Pozzi, J. A. Mullens, and J. T. Mihalczo, "Analysis of Neutron and Photon Detection Position for the Calibration of Plastic (BC-420) and Liquid (BC-501) Scintillators," Nuclear Instruments and Methods in Physics Research A 524, nos. 1-3 (2004): 92-101. 